\title{
Predictive Analytic Game-based Model for Yoruba Language Learning Evaluation
}

\author{
Ayodeji O.J Ibitoye \\ Department of Computer Science and Information Technology, Bowen University, Iwo, Osun State, Nigeria. \\ Email: Ibitoye_ayodeji@yahoo.com \\ Opeyemi T. I Olaifa \\ Department of Computer Science and Information Technology, Bowen University, Iwo, Osun State, Nigeria
}

Received: 08 March 2017; Accepted: 29 November 2017; Published: 08 February 2018

\begin{abstract}
Be it indigenous or foreign language, languages are core for communicating messages from one person to another or group of persons. Primarily, it is learnt at home, schools, through the media like television and radio programmes. However, most of these language-teaching approaches do not measure the percentage growth of people who have gained the knowledge of the language over the years; they also lack the capacity to foretell the range of people that will acquire the knowledge of the language in the latest future. This is because several of the language teaching aids do not have the required dataset to describe and effectively predict the state of the language (a category of people who can speak and write the language) now, and against the future. Here, the research proposed an analytic game based model for Yoruba language evaluation. The essence is first to ascertain the user's initial knowledge of a language, train users through difference fun filled game stages and levels, evaluate the user at the end of every level and analyse the clustered dataset of users game points to describe and predict the state of the language by using a dual level predictive analytics technique.
\end{abstract}

Index Terms-Predictive Analytic, edutainment, Yoruba language, game, game-based model, clustering, linear regression.

\section{INTRODUCTION}

Language is known as a vocal values shared by a group of people that are connected by common and natural trust. It is a requirement for effective learning since language serves as a guide for thinking and a necessity for good communication [1]. The indigenous language, which is our mother's tongue, is a very crucial language in the development stage of skills acquisition, language acquisition and educational attainment [2]. However, there are diverse learning process, which has been used in order to help improve the learning of a language. The Media, through the television and radio has been a great platform where the language and culture of the language are being passed to viewers and listeners respectively. Another learning process can take place through teacher to the student where the teacher teaches the student about the language and culture. Also, as part of the ways to help improve the learning of languages, edutainment mediums which is learning through entertainment has becomes an effective approach. The word "edutainment" is a compound of two words of "education" and "entertainment". While education is the gradual process of acquiring knowledge, entertainment is an activity that is sustaining the attention of the trainee to make learning less rigid [3]. These activities are being propelled to make trainees' have fun and in the process acquire the necessary knowledge and skills. In such situation, the concerned person thinks about the process and discovered what they have gained and thus, unconsciously have being educated [4]. Therefore, learning with fun shows to be more effective as long as it contains learning, motivational and interactive components. [5]. No doubt games playing is a major edutainment tool because it enhances learning through experimentation, visualization and creativity of play [6]. It is also capable of making learning relaxed. fun filled and also help to build players' confidence [7]. Game based learning system is intrinsically motivated i.e., playing the game would be voluntary and self-driven, experimental learning, self-reliance, goal oriented and fun based. A player's curiosity and motivation are stirred by their determination to challenge the various levels and prevail [8]. However, major games created for learning purposes like mind snack, busuu, duolingo are centred towards passing knowledge and fun to the players alone without taking proper analysis of how far the game has improved the players over a short or long period of time. Thus, majority of these types of games are not analytical and cannot be used to describe and predict the number of players that may have learnt or would learn through the game in the nearest future.

\section{RELATED WORKS}

There are several areas in which the use of game has been used to support learning. These areas include, mathematics, Arts, languages among others. We would therefore consider a review on implementing a game to 
support learning in language [9]. Language learning through gameplay can happen in a wide variety of ways, from a planned learning activity in an instructional environment to an incidental by-product of a gamer's interactions with the game and its associated online activities. [10] Just as a Web-based spoken translation game aimed at providing language learners with an easily accessible and fun environment to practice speaking the foreign language, the prototype centres on the task of translating flight domain sentences from English to Chinese. Thereby, the system presents English sentences as stimuli to elicit Chinese utterances from a user. It tracks a user's performance and rewards them with advancements in difficulty level. Video games have also been used in language learning. [11] also studied the influence of using games in teaching English to learners. The method uses library method to collect data in the field of internal and external studies. The sample group was divided equally to two groups, control and experimental group while data Analyses and testing the rate of meaning of research assumptions were used via SPSS software $\{12,13]$. Unlike the traditional method of learning and teaching, in a communicative language teaching (CLT) approach, learners are required to take part in a number of meaningful activities with different tasks [14]. Thus, Speech and language technologies have great potential in Computer Aided Language Learning (CALL) applications. Also, a voice-interactive system can play the role a language teacher and a conversational partner, in order to provide the learner with endless opportunities for practice and feedback [15, 16]. Examples of language learning mobile app games are Duolingo and Bussu. With Duolingo, the languages available depend on the players' mother tongue. it's a language app that provides a free language education for the world. By unlocking bite-sized activities at each level of the game, players advance in the game's progress indicator. Busuu offers different learning opportunities, both individual and collaborative [17]. The game menu displays the gamer's photo or image and includes five sections: courses, help others, exercises, preferences, and Contact us. It goal is to offer opportunities to learn the most important 150 topics and 3,000 words. Since games have become an important social trend, many educators have confidence that, if used properly, they can become an important instructional tool. Thus, in each language learning game, [18] teaching aim is always located behind the aim of the game. The importance of the games is to deepen the language learning process in such a way that the game playing serves as tools for cognitive and mental process activation.

\section{Proposed Predictive Analytic Game Based MODEL}

For games to play an effective learning and analytic activities role, they should provide content relevant to the language course and a concise dataset for pattern analysis. With the language teacher perspective in mind and taking into consideration that mobile devices are the fastest growing technology platform in the developing world, the upsurge of new mobile devices has created a new standard for mobile communications and media. Therefore, to effectively illustrate the proposed Yoruba language analytic game based system, the concept and design is divided into 4 interconnected modules.

\section{a. Registration mechanism \\ b. User Language Knowledge Mechanism \\ c. Learning Points Mechanism \\ d. Predicting Mechanism}

\section{A. Registration mechanism}

Once a user downloads the mobile app, every user must login by registering their name, sex, location and other biodata to gain access to the functionalities of the computer aided language learning system in order to obtain a player identification number. The app ensures that no two registered players has the same identity number. This is to ensure proper pattern analysis for effective description and prediction paradigms.

\section{B. User Language Knowledge Mechanism:}

Since it is a learning game, the initial knowledge of the player about the language is being evaluated and gathered through an elementary intelligent question (IQ) test. The essence is to assess the player at the beginning of the game, use the score obtained from the IQ test to classify the level and stage to which a user belongs; thereafter, launch the appropriate game level where the user can start off learning. The proposed language learning game has different stages like Beginner, Intermediate, and Expert whereas, each stages also contain different playing levels. Courses are introduction at each stage. Each lesson offers a set of activities. This include: translating a sentence from written input, fill in the gap, choosing the picture and word for a vocabulary item, typing what you see from text input, choosing all the right translations from a list of text input, and repeating a sentence from oral input. Thus, most players are likely not to commence training with the game on the same level. While a cluster of different players with same startup are clustered as pattern for latter analysis.

\section{Learning points Mechanism:}

By playing the game, points are being generated for the player to move from one level to another and from one stage to another. This points are represented in one's and zero's as for correct and incorrect points respectively. At the end there is an average score that a player must earn in order to move to the next level or stage as it may be. However, a player is meant to repeat a failed level after the solution(s) to the missed test have been provided. More so, when the player as earned the right score to unlock the next stage. The solution to be missed items are also provided. To this end, there is an evaluation and recap at the end of every level before preceding to the next. The essence is to ascertain that indeed; the knowledge is well gained by the player through fun. 


\section{The Predictive Mechanism}

The predictive data mining technique perform inference from the current data for making prediction. It works by making a prediction about values of data, which uses known results found from different dataset. Here, the analytical approach begins with pre-processing, in which the raw data i.e. the player id, points gathered at different level and stages of the game is extracted from the database and transformed into a usable format. Two predictive data mining techniques are employed here. The first is the clustering technique while the other is the Linear Regression after defining the target value for the prediction. Here, the proposed predictive game based model for language evaluation processes is further illustrated in Fig 1 below.

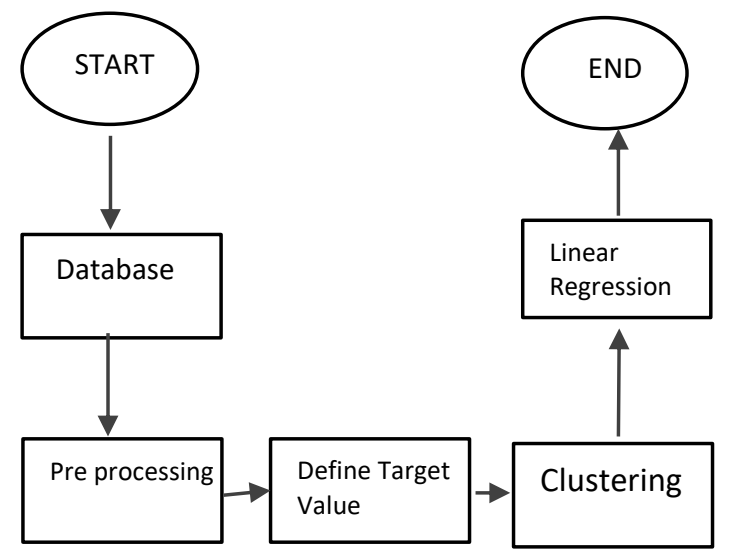

Fig.1. Game-Based Analytic Predictive Phase

Since every data score point is assigned a real valued weight, clustering, being an example of unsupervised learning is engaged in this process. Unsupervised learning approach is a machine learning paradigms that is used to learn from the datasets, even though we do not know what to label, this particular data is applied to the dataset to extract patterns, which can be used for prediction. Thus, a set of data items based on weighted scores of game players is partitioned into a set of classes also called as groups. The clustering algorithm is mainly used to finding groups of similar players with same level of knowledge gained by playing the language learning game. Here, a sample k-means algorithm as presented in Fig 2 below is used.

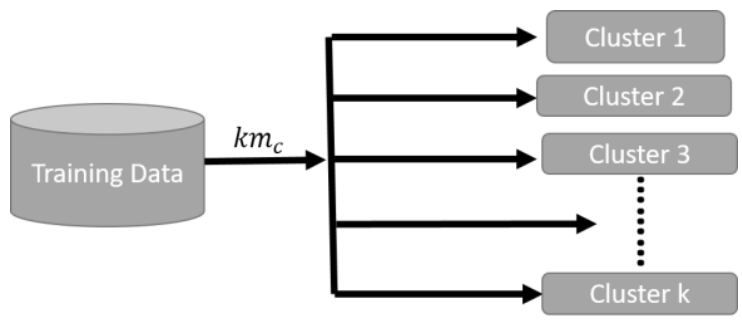

Fig.2. clustered Data from Training set

$\mathrm{km}_{\mathrm{c}}$ is the $\mathrm{K}$-means clustering algorithm that works on the in table 1 below
Table 1. K-Means algorithm for data clustering

Input: Dataset of players and games played

Output: k clustered patterns of player

1. Clusters the data into $\mathrm{k}$ groups where $\mathrm{k}$ is predefined.

2. Randomly select $\mathrm{k}$ points as cluster centres.

3. According to the Euclidean distance function, assign objects to their closest cluster center

4. Calculate the centroid or mean of all objects in each cluster.

5. Iterate steps 2, 3 and 4 until the same points are assigned to each cluster in consecutive loop

After this clustering, we used the linear regression technique to analyse the dependency of some attribute values, which is dependent upon the values of other attributes that is present in the domain of weighted clusters. Since linear regression is targeted here at numerical attributes, then, a line that best fits the data is calculated, that is, the line that minimizes the average distance of all the points from the line. This line becomes a predictive indicator when the value of the dependent variable is not known; its value is predicted by the point on the line that corresponds to the values of the independent variables for that record. The essence is to use the result obtained to predict new cases or existing players and the potential once. Since, there is an increase in the demand for teaching languages to young learners, no doubt game based learning will have a significant role to play because there is a strong connection between game based learning and language learning both in and outside school. When the appropriate resource is given to a developer, then language learning games that target particular linguistic or cultural topics can be successful, particularly if they are used in the context in which learners are highly motivated by external factors.

\section{Model Evaluation}

The model is experimented with the Yoruba Language. The Yoruba's are about 40 million people in total with the majority constituent from Nigeria. They constitute about $21 \%$ of Nigeria's population, 1.2 million in Benin, 0.4 in Ghana, 0.1 in Togo, 0.1 in Ivory Coast, 0.2 in Europe and 0.2 in North America. Aside the fact the authors of this research work are indigenous Yoruba people, the choice of the language for modelling is also based on the research observation that Yoruba language is been endangered, and may likely go into extinction since the rate at which it's been used among the language owner for meaningful purpose in the community is drastically reducing, Also, it is not being transmitted to the younger generation approximately (especially from parent to children) and very few speakers or writers of the Language at the moment remains the old once. Thus, the game was tested by 500 voluntary players and the following evaluations are obtained as presented in the figures and tables below. 
Table 2. Results of the descriptive analysis for the game players

\begin{tabular}{|l|l|l|l|}
\hline Variable & Category & Number & Percentage (\%) \\
\hline Gender & Female & 115 & 23 \\
\cline { 2 - 4 } & Male & 385 & 77 \\
\hline $\begin{array}{l}\text { Prior Online Game } \\
\text { Experience }\end{array}$ & Yes & 305 & 61 \\
\cline { 2 - 4 } & No & 195 & 39 \\
\hline $\begin{array}{l}\text { Prior Yoruba Game } \\
\text { Experience }\end{array}$ & Yes & 42 & 8.4 \\
\cline { 2 - 4 } & No & 458 & 91.6 \\
\hline
\end{tabular}

Sequel to the assessment test as indicated in section 3 above, the table two below shows the language level of the players before the game.

Table 3. Initial Knowledge assessment of players understanding of the Language before the game

\begin{tabular}{|l|l|l|ll|l|ll|}
\hline Variable & Category & $\begin{array}{l}0- \\
39 \%\end{array}$ & $\begin{array}{l}40 \\
59 \%\end{array}$ & $\begin{array}{l}60- \\
69 \%\end{array}$ & $\begin{array}{l}70 \\
100 \%\end{array}$ & - \\
\hline Gender & Female & 52 & 37 & 20 & 6 \\
& & & & & \\
\cline { 2 - 7 } & Male & 173 & 190 & 6 & 16 \\
\hline
\end{tabular}

Based on the game structure, players below $60 \%$ starts the level from the simplest, while player with less than $69 \%$ but greater than $59 \%$ begins on the intermediate stage as players with $70 \%$ begins at the expert stage. Thus, figure 2 below describe the start-up game playing level by players.

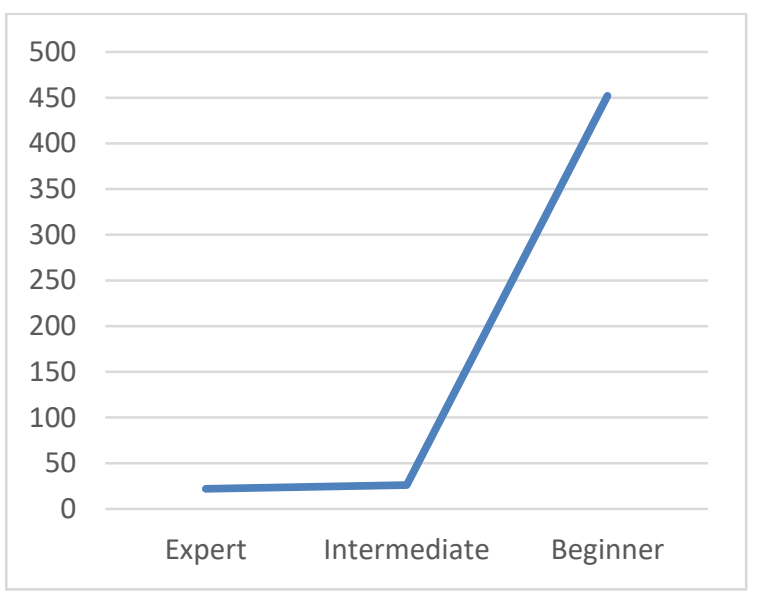

Fig.2. Start up Game Level for Players

From the figure 2, $90.4 \%$ of the players started the game at the beginners' level while $5.2 \%$ began at the intermediate stage with just $4.4 \%$ displaying a good knowledge of the language and starting at the expert stage. From the $90.4 \%$ that started the game from the beginner's stage, a $65 \%$ improvement in the knowledge of the language was obtained from the $72 \%$ players that completed the game.

\section{CONCLUSION}

In this research, an improved method of teaching and evaluating the knowledge acquired through an analytic game based model for language was introduced. Most of the traditional approaches have only focus on training while neglecting the descriptive and pattern analysis phase which aids predictions. Here, clustering and linear regression analytic techniques was introduced on the weighted score of players from the beginning to the end. Thus, a pattern is obtained and this can be used to establish the probability of what the state of a language is going to be in the nearest future. No doubt, one of the main advantages to using the proposed analytical language learning game is its ability to track data in order to be able to ascertain how the game is being played, to correlate game activity with individual learner outcomes and attitudes for effective prediction.

\section{REFERENCES}

[1] Adesuyan, A. (1998). Indigenous languages for education the Yoruba example.In O. arohunlase (Ed.) Nigerian languages for national development and unity .Ibadan: Lolycn Communication.

[2] Adenegan, k. E., Raji, S. M. \& Adenegan, t. S (2014). The use of yoruba indigenous language in the teaching and learning of mathematics in nigerian schools. International Journal of Science and Science Education, Vol. 5(1), pp. $53-59$

[3] Meyer, B. (2010) 'Learning English through serious games - reflections on teacher and learner performance' Transactions on Edutainment III. Berlin: Springer, pp. 8292

[4] Connolly, T., Stansfield, M. \& Hainey, T. (2011). An alternate reality game for language learning: ARGuing for multilingual motivation. Computers \& Education 57(1), 1389-1415.

[5] Boyle, E., \& Conolly, T. (2008). Games for learning: Does gender make a difference? In T. Conolly \& $\mathrm{M}$. Stansfield (Eds.), Proceedings of the 2nd European Conference on Games Based Learning (pp. 69-76). Reading, UK: Academic Publishing.

[6] Susan .B "An introduction to game based learning"2011

[7] Serrano, A., Marchiori, E.J., del Blanco, A., Torrente, J., Fernandez-Manjon, B.: (2012) A framework to improve evaluation in educational games. In: Proceedings of the 2012 IEEE Global Engineering Education Conference (EDUCON), pp. 1-8

[8] Liu C-C, Cheng Y-B, Tsai C-C, Huang C-C. (2011) The effect of simulation games on the learning of computational problem-solving. ComputEduc.; 57(3):1907-1918.

[9] Cornillie, F., Clarebout, G., \& Desmet, P. (2012). Between learning and playing? Exploring learners' perceptions of corrective feedback in an immersive game for English pragmatics. ReCALL, 24(3), 257- 278.

[10] Hamzeh Sharifial And Mandana Sharifib "A Survey On The Influence Of Using Games In Teaching English To Girl Learners In Age Group 12-14. Indian journal of scientific research

[11] Jonker, V., \& van Galen, F (2004). KidsKount. Mathematics games for realistic mathematics education in primary school. Paper presented at: 10th International Conference on Mathematics Education (ICME), Kopenhagen, Denmark 
[12] Mor, Y., Winters, N., Cerulli, M.\&Björk, S (2006). Literature review on the use of games in mathematical learning, Part I: Design. Report of the Learning Patterns for the Design and Deployment of Mathematical Games project

[13] Chang, B., Sheldon, L., Si, M., \& Hand, A (2012). Foreign language learning in immersive virtual environments, In Proceedings of the IS\&T/SPIE Electronic Imaging, (pp. 2-9). Burlingame, CA: SPIE Digital Library.

[14] Hwang, G.-J., Wu, P.-H.: (2012) Advancements and trends in digital game-based learning research: a review of publications in selected journals from 2001 to 2010. Br. J. Educ. Technol. 43(1), E6-E10

[15] Euler (2011). The PRIMAS project: Promoting inquirybased learning (IBL) in mathematics and science education across Europe. Retrieved April 15, 2012

[16] Egenfeldt-Nielsen, S., Sørensen, B. H. and Meyer, B. (eds.) (2011) Serious Games in Education - a Global Perspective. Aarhus: Aarhus University Press

[17] Kumar A., Tewari, A., Shroff G., Chittamuru, D., Kam, M. \& Canny, J. (2010). An exploratory study of unsupervised mobile learning in rural India. In Proceedings of the SIGCHI Conference on Human Factors in Computing Systems (pp. 743-752). New York, NY: ACM

[18] Melhuish, K. \& Falloon, G. (2010)' Looking to the future: M-Learning with the iPad', Computers in New Zealand Schools: Learning, teaching, technology, vol. 22, no. 3, pp.1-15

\section{Authors' Profiles}

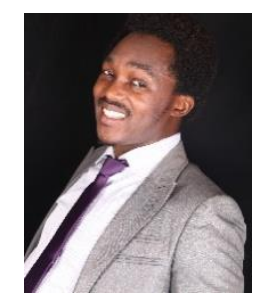

Ayodeji O.J Ibitoye lectures at the Department of Computer Science and Information Technology, Bowen University, Iwo, Nigeria. He obtained his B.Sc. and M.sc Computer Science from the prestigious University of Ilorin, Ilorin Kwara State and University of Ibadan, Ibadan, Oyo state in 2009 and 2014 respectively. $\mathrm{He}$ is a young innovative and resourceful researcher with great analytic and programming skills. His Research Interest is in Big Data Analytics, Information Retrieval, Biometrics intelligent Applications, Fuzzy learning, and Knowledge Organization. He has several peered reviewed publications in journals and conferences in his field of expertise.

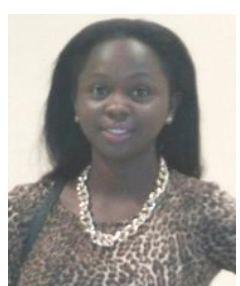

Opeyemi T.I Olaifa obtained a Bachelor's Degree in Computer Science from Bowen University Iwo, Osun State, Nigeria in 2016. She is a young, goaloriented, innovative and hardworking woman with great analytical and programming skills. Her research interest is in Computing Science, Information Retrieval and Data Analytics.

How to cite this paper: Ayodeji O.J Ibitoye, Opeyemi T. I Olaifa, " Predictive Analytic Game-based Model for Yoruba Language Learning Evaluation", International Journal of Modern Education and Computer Science(IJMECS), Vol.10, No.2, pp. 43-47, 2018.DOI: 10.5815/ijmecs.2018.02.05 